\title{
Esophageal inlet patch: Endoscopic prevalence in full sedated patients and Clinical significance.
}

\author{
Remzi BESTAS ${ }^{1}$ and Nazım Ekin ${ }^{2}$ \\ ${ }^{1}$ Dicle memorial hospital \\ ${ }^{2}$ Health Sciences University Diyarbakır Gazi Yaşargil Training and Research Hospital
}

March 14, 2021

\begin{abstract}
AIM: To determine the frequency, demographic and clinical features of the heterotopic gastric mucosa (inlet patch). MATERIALS AND METHODS: This retrospective study involves 244 patients who applied to the gastroenterology outpatient clinic with different symptoms between September 2016 and December 2019, and who were diagnosed with inlet patch in elective esophagogastroduodenoscopy. All endoscopic procedures were performed by the same clinical endoscopist. All medical records of patients including demographic and clinical features and endoscopy findings were reviewed. RESULTS: Considering 2823 patients who underwent elective esophagogastroduodenoscopy in the same study period, inlet patch was detected in 224 (8.6\%). $56.6 \%$ of the patients diagnosed with inlet patch were male and there was no statistical difference between the two genders. The mean age of the patients was $37.73 \pm 13.01$ years. $83.6 \%$ of the patients had only one lesion, and $58.2 \%$ had a lesion larger than $1 \mathrm{~cm}$, with the largest one being $4.5 \mathrm{~cm}$. Size of the smallest lesion was $0.3 \mathrm{~cm}$. All of the lesions were in the proximal esophagus. 54 patients $(22.1 \%)$ had at least one supraesophageal or upper esophageal symptom. The most common symptom was globus sensation $(64.8 \%)$. Patients with large lesions were more likely to experience symptoms $(28.2 \%$ vs. $13.7 \%$, $\mathrm{p}=0.008)$. CONCLUSION: Careful examination of the proximal esophagus may increase the chance of detecting inlet patch and may explain persistent symptoms in patients without a specific cause. Further understanding of the clinical significance of the disease may also prevent unnecessary diagnostic interventions.
\end{abstract}

\section{Hosted file}

\selectlanguage\{polish\} $\dot{I} \backslash$ selectlanguage\{english\}P.IJCP.pdf available at https://authorea. com/users/401494/articles/513567-esophageal-inlet-patch-endoscopic-prevalence-in-fullsedated-patients-and-clinical-significance 

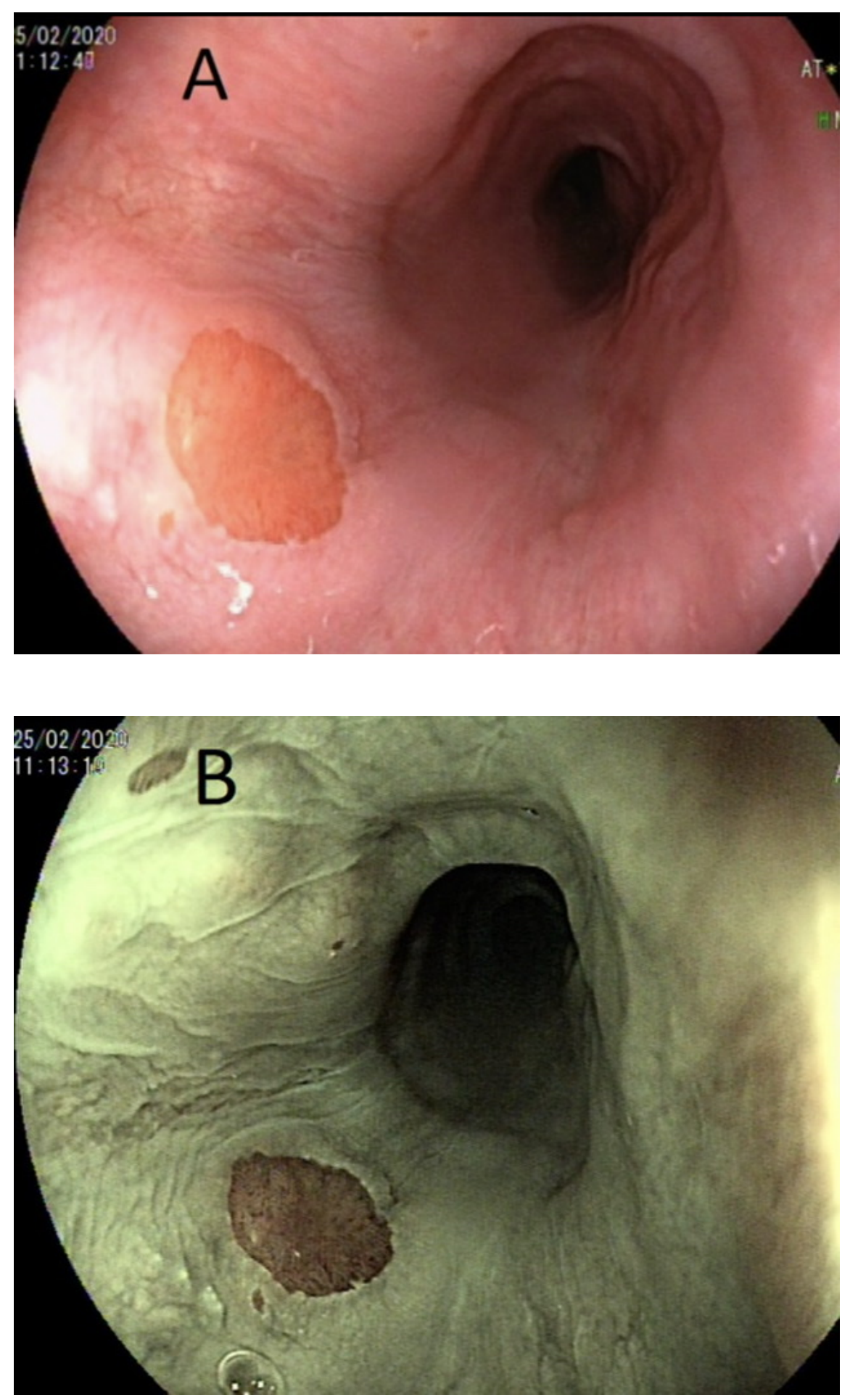

\section{Hosted file}

Table 1.pdf available at https://authorea.com/users/401494/articles/513567-esophageal-inletpatch-endoscopic-prevalence-in-full-sedated-patients-and-clinical-significance 


\section{Hosted file}

Table 2.pdf available at https://authorea.com/users/401494/articles/513567-esophageal-inletpatch-endoscopic-prevalence-in-full-sedated-patients-and-clinical-significance 